\title{
In vitro Study of Urtica cannabina and Leymus chinensis on Rumen Microbial Fermentation and Gas Production
}

\author{
Zhenbin Zhang, Shan Wang, Ruxin Qi, Khuram Shahzad',
} Liangfeng Shi, Xiaoqing Zhang², Mengzhi Wang

10.18805/IJAR.B-1291

\begin{abstract}
Background: Urtica cannabina, an unconventional forage, is widely distributed in northern China. It has high nutritional values that make it suitable for the ruminant's feeding requirments as compared to Leymus chinensis. The current study was designed to evaluate varying ratios of Urtica cannabina and Leymus chinensis in the feeding diet and to see the effects on rumen fermentation and gas production in vitro.

Methods: The study was designed into five treatments based on the different ratios of $U$. cannabina and L. chinensis: 0:100, 30:70, 50:50, 70:30 and 100:0 categorized into five groups from A-E. To detect the rumen fermentation parameters, the culture medium was collected at 1, 3, 6, 12 and $24 \mathrm{~h}$.

Result: Gas production of groups A and $\mathrm{C}$ was increased than other groups at $24 \mathrm{~h}(P<0.05)$, whereas the rate of gas production $(C)$ was also increased in group $\mathrm{A}(P<0.05)$. The $\mathrm{pH}$ values at $1,3,6$ and $24 \mathrm{~h}$ were increased in groups $\mathrm{A}$ and $\mathrm{C}$ with higher values in group $C$ at $24 \mathrm{~h}(P<0.05)$. The ammonia concentration was increased in groups $D$ and $E$ at $3,6,12$ and $24 \mathrm{~h}$, with the lower values in group $\mathrm{C}$ at $24 \mathrm{~h}(P<0.05)$. The concentration of bacterial and protozoal proteins was also observed higher in groups $\mathrm{A}$ and $\mathrm{C}$ at 1 and $24 \mathrm{~h}$, with highest value in group $\mathrm{C}$ at $24 \mathrm{~h}(P<0.05)$. In summary, as for Urtica cannabina to Leymus chinensis ratios are concerned, 50:50 is an optimal ratio for rumen fermentation in vitro, which increases the gas production and microbial protein synthesis.
\end{abstract}

Key words: Gas production, In vitro, Leymus chinensis, Rumen fermentation, Urtica cannabina.

\section{INTRODUCTION}

High-quality forage is essential for the growth and development of ruminants. Nowadays, the quantity of highquality forage is insufficient in the ruminant industry in China (Xie et al. 2019). Some studies demonstrated that an unconventional forage with high nutritional values can substitute for ruminant feed sources (Iniguez, 2011; Porqueddu et al. 2016).

As an unconventional forage, Urtica cannabina is widely distributed in Xinjiang, Inner Mongolia and other places because of its strong vitality and adaptability (Zhang et al. 2014). Usually, the yield range of this plant is 3.6-7.8 $\mathrm{t} \mathrm{ha}^{-1}$ without chemical fertilizers, while under good environment and nutrition conditions, the dry matter yield of the natural $U$. cannabina can reach to $14 \mathrm{t} \mathrm{ha}^{-1}$ (Zhang and Zhao, 2008). It's stem and leaves are rich in protein, trace elements, cellulose and a variety of active substances (Zhang et al. 2020). Medically, it has been used in the treatment of diseases such as rheumatoid arthritis and prostatitis syndrome, etc. (Bourgeois et al. 2016; Carvalho et al. 2017). In recent years, $U$. cannabina has been used in livestock production. It has already been demonstrated by that $U$. cannabina is involved in improving morphological features of gastrointestine and nutrients digestibility in lamb (Jin et al. 2018). Humphries and Reynolds (2014) reported that Urtica dioica haylage (100 g/kg DM) increased milk production in the diet of lactating dairy cows instead of ryegrass silage. However, little is known about the effects of $U$. cannabina on rumen microorganisms, it may alter
College of Animal Science and Technology, Yangzhou University, Jiangsu Yangzhou-225009, China.

'Department of Bioscience, COMSATS University Islamabad, Park Road, Islamabad-45550, Pakistan.

${ }^{2}$ Institute of Grassland Science, Chinese Academy of Agricultural Sciences, Inner Mongolia Huhehote-010010, China.

Corresponding Author: Mengzhi Wang, College of Animal Science and Technology, Yangzhou University, Jiangsu Yangzhou-225009, China. Email: mengzhiwangyz@126.com

How to cite this article: Zhang, Z., Wang, S., Qi, R., Shahzad, K., Shi, L., Zhang, X. and Wang, M. (2021). In vitro Study of Urtica cannabina and Leymus chinensis on Rumen Microbial Fermentation and Gas Production. Indian Journal of Animal Research. DOI: 10.18805/IJAR.B-1291.

Submitted: 25-05-2020 Accepted: 07-11-2020 Online: 28-01-2021

rumen microbial activity because it indeed contains many biologically active compounds. So we hypothesized that the addition of $U$. cannabina can increase rumen microbial activity in vitro. Therefore, the effects of $U$. cannabina to $L$. chinensis ratios on the rumen fermentation in vitro were investigated in the present study.

\section{MATERIALS AND METHODS}

The study was carried out during the period of July 2017 to June 2018, at the Institute of Metabolic Manipulation of Herbivorous Animal Nutrition, College of Animal Science and Technology, Yangzhou University, China. 
In vitro Study of Urtica cannabina and Leymus chinensis on Rumen Microbial Fermentation and Gas Production

\section{Animal management}

The following experimental procedures, including animal ethics and usage, were approved by the Animal Welfare Committee which is managed by Yangzhou Veterinarians of the Agriculture Ministry of China.

Two-year-old, three healthy Xuhuai goats having permanent rumen fistulas with body weight $(B W \pm S D)$ of $35 \pm 3.1 \mathrm{~kg}$ were chosen for the sampling purpose from the experimental farms of Yangzhou University. The diet offered to goats (dry matter amount about $3 \%$ BW) was mixed well with following contents including $70 \%$ alfalfa, $28 \%$ corn kernels and $2 \%$ soybean meal. This diet was fed to goats in equal amounts at 07:00 $\mathrm{h}$ and 19:00 $\mathrm{h}$. They had free access to mineral licking blocks and fresh drinking water.

\section{Culture substrate and experimental design}

The samples of $U$. cannabina were collected early in July 2017 during the flowering stage and the samples of $L$. chinensis were bought from Caodu Co., Ltd. The forages were automatically collected and dried outside in an open environment in Xilinguole, Inner Mongolia region, China.

$U$. cannabina and $L$. chinensis were dried at $65^{\circ} \mathrm{C}$ to a constant mass in a force air oven and then ground finely with a Retsch ZM 100 Wiley mill (Retsch $\mathrm{GmbH}$, Haan, Germany) to pass through $1 \mathrm{~mm}$ screen. These two kinds of refined grass were mixed in proportion as the in vitro culture substrates with the following five ratios: 0:100, 30:70, 50:50, 70:30 and 100:0 categorized into the five groups from $A-E$ respectively. The ingredient and nutritive values of each group are shown in the Table 1.

\section{In vitro gas production test}

The rumen fluid samples were collected from different localities through the rumen fistula using a vacuum negative pressure device (self-constructed) before morning feeding. These samples were filtered into a thermos flask containing four layers of gauze. The flask was filled with $\mathrm{CO}_{2}$ and heated at $39{ }^{\circ} \mathrm{C}$ before collecting samples. The artificial saliva salt was configured according to Menke and Steingass (1988). The culture medium for in vitro culture of rumen microorganisms was prepared using artificial saliva salt with rumen fluid ratio $2: 1$. Then $\mathrm{CO}_{2}$ was introduced for saturation purpose. The substrate of each group weighed $0.5000 \mathrm{~g}$ $( \pm 0.0500 \mathrm{~g})$ accurately in a $150 \mathrm{~mL}$ fermentation bottle and $50 \mathrm{~mL}$ of artificial saliva and $25 \mathrm{~mL}$ of rumen fluid were added later on. Each treatment in sampling time was replicated three times. The culture bottle was connected to the 64way microbial fermentation micro-product gas automatic recorder (AGRS-III, Beijing, China). The incubation temperature was set to $39^{\circ} \mathrm{C}$ and incubated for $24 \mathrm{~h}$ at constant temperature under anaerobic conditions.

\section{Sample collections and chemical analysis}

Gas production was recorded at 1, 3, 6, 12 and $24 \mathrm{~h}$ of incubation. The kinetics of gas production in vitro were calculated according to the exponential function model proposed by Ørskov and McDonald (1979). The culture medium at each time point was filtered through the four layers of gauze and dispensed in $5 \mathrm{~mL}$ centrifuge tubes. The $\mathrm{pH}$ value of the rumen fluid was measured immediately using an electrode $\mathrm{pH}$ meter (pHS-3C, Shanghai, China). The rumen fluid was immediately stored for analysis of ammonia nitrogen, bacterial and protozoal proteins at $-20^{\circ} \mathrm{C}$. The ammonia nitrogen concentration was measured by the phenol-sodium hypochlorite colorimetric method (Weatherbum, 1967). The bacterial and protozoal protein concentrations in rumen fluid were determined according to the method as described by Hall et al. (2001).

\section{Statistical analysis}

Statistical analysis was performed by SPSS software (version 16.0, SPSS Inc., Chicago, USA) using ANOVA procedure with posthoc tukey's multiple comparison test. The fixed effect was treatment and sampling time, whereas random effect in the ANOVA model was repetition. Significance was declared at $p$-value $<0.05$.

\section{RESULTS AND DISCUSSION}

\section{Effects on the kinetics of gas production in vitro}

In our study, gas production of different groups increased with fermentation time (Fig 1). Whereas gas production was increased in the groups $A$ and $C$ at $24 \mathrm{~h}(P<0.05)$. The data in Table 2 show that the gas produced from soluble fraction (a) was higher $(P<0.05)$ in groups $D$ and $E(1.83$ and $2.10 \mathrm{~mL} /$ $g$ DM), whereas the gas produced from insoluble but fermentable fraction $(\boldsymbol{b})$ produced was lower $(P<0.05)$ in group $E(41.01 \mathrm{~mL} / \mathrm{g} D M)$. The highest value was registered

Table 1: Ingredient composition and nutritive value of substrate.

\begin{tabular}{lccccc}
\hline \multirow{2}{*}{ Item } & \multicolumn{5}{c}{ Group treatment } \\
\cline { 2 - 6 } & $\mathrm{A}$ & $\mathrm{B}$ & $\mathrm{C}$ & $\mathrm{D}$ & $\mathrm{E}$ \\
\hline Ingredient (\%) & & & & & \\
U. cannabina & 0 & 30 & 50 & 70 & 100 \\
L. chinensis & 100 & 70 & 50 & 30 & 0 \\
Total & 100 & 100 & 100 & 100 & 100 \\
Nutritive level $\mathbf{( g / k g )})^{1}$ & & & & \\
CP & 87.3 & 110.61 & 126.15 & 141.69 & 165 \\
EE & 25.4 & 26.48 & 27.2 & 27.92 & 29 \\
NDF & 670 & 583.6 & 526 & 468.4 & 382 \\
ADF & 302 & 301.7 & 301.5 & 301.3 & 301 \\
NFC & 153 & 177.6 & 194 & 210.4 & 235 \\
Lignin & 86.5 & 71.98 & 62.3 & 52.62 & 38.1 \\
Ash & 63.8 & 101.36 & 126.4 & 151.44 & 189 \\
Ca & 5.1 & 13.89 & 19.75 & 25.61 & 34.4 \\
P & 1.2 & 5.64 & 8.6 & 11.56 & 16 \\
\hline
\end{tabular}

${ }^{1}$ Nutritional value was measured; $\mathrm{CP}=$ Crude protein; $\mathrm{EE}=\mathrm{Ether}$ extract; NDF=Neutral detergent fibre; $A D F=$ Acid detergent fibre; $\mathrm{NFC}=$ Non-fibre carbohydrates $=1000-(\mathrm{CP}+\mathrm{EE}+\mathrm{NDF}+\mathrm{ash})$; $\mathrm{Ca}=$ calcium; $\mathrm{P}=$ phosphorus.

Legends: Ratio of $U$. cannabina to $L$. chinensis in groups A-E are $0: 100,30: 70,50: 50,70: 30$ and 100:0 respectively. 
Table 2: Effects of the kinetics of gas production of each group in vitro.

\begin{tabular}{|c|c|c|c|c|c|c|c|}
\hline \multirow{2}{*}{ Items } & \multicolumn{5}{|c|}{ Group treatment } & \multirow{2}{*}{ SEM } & \multirow{2}{*}{$P$-value } \\
\hline & $A$ & $\mathrm{~B}$ & $\mathrm{C}$ & $\mathrm{D}$ & $E$ & & \\
\hline$a^{1}$ & $1.36^{b}$ & $1.22^{\mathrm{b}}$ & $1.67^{\mathrm{ab}}$ & $1.83^{\mathrm{a}}$ & $2.10^{\mathrm{a}}$ & 0.13 & $<0.01$ \\
\hline$b^{2}$ & $62.76^{a}$ & $54.51^{\mathrm{a}}$ & $57.03^{a}$ & $55.17^{a}$ & $41.01^{b}$ & 2.17 & $<0.01$ \\
\hline$c^{3}$ & $0.201^{\mathrm{a}}$ & $0.128^{c}$ & $0.167^{b}$ & $0.095^{d}$ & $0.029^{e}$ & 0.01 & $<0.01$ \\
\hline$a+b^{4}$ & $64.12^{\mathrm{a}}$ & $55.71^{a}$ & $58.70^{a}$ & $56.99^{a}$ & $43.10^{b}$ & 2.09 & $<0.01$ \\
\hline
\end{tabular}

1 = gas produced from soluble fraction $(\mathrm{mL} / \mathrm{g} \mathrm{DM})$.

2 = gas produced from insoluble but fermentable fraction ( $\mathrm{mL} / \mathrm{g} \mathrm{DM})$.

$3=$ rate constant of gas production during incubation $\left(\mathrm{mL} / \mathrm{h}^{-1}\right)$.

4 = potential gas production $(\mathrm{mL} / \mathrm{g} \mathrm{DM})$.

Legends: Ratio of $U$. cannabina to $L$. chinensis in groups A-E are 0:100, 30:70, 50:50, 70:30 and 100:0 respectively.

a-e: values in the same row with different small superscript letters are different from each other significantly $(P<0.05)$.

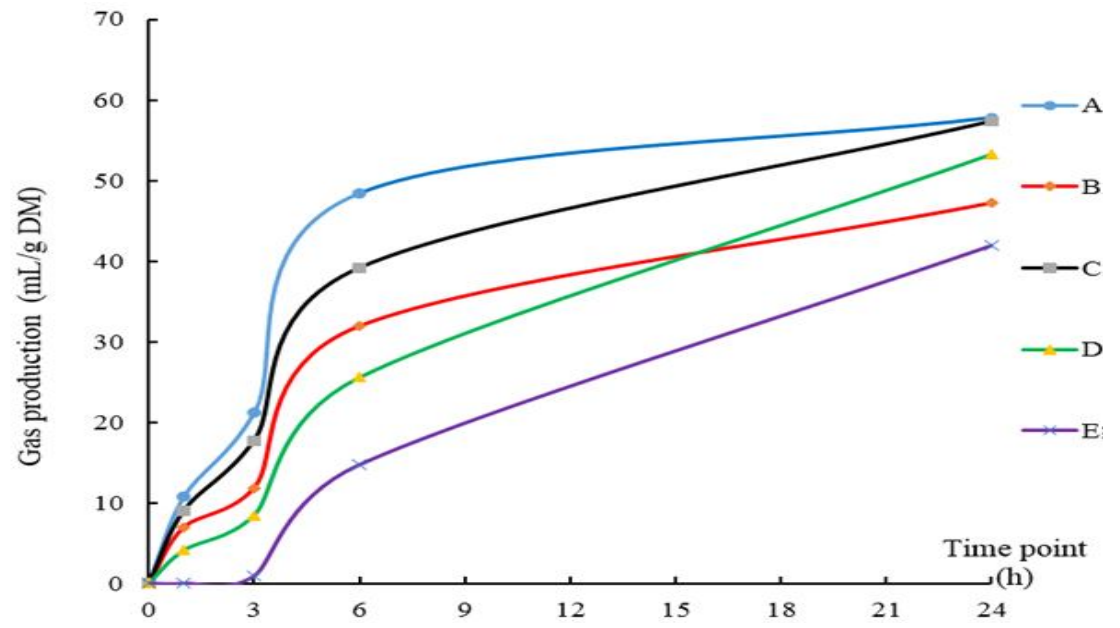

Fig 1: Cumulative gas release of different ratios of $U$. cannbinau to $L$. chinensis in vitro(mL/g DM).

Legends: Ratio of $U$. cannabina to $L$. chinensis in groups A-E are 0:100, 30:70, 50:50, 70:30 and 100:0 respectively.

for group $\mathrm{A}(62.76 \mathrm{~mL} / \mathrm{g} D M)$. The rate of gas production (c) was higher $(P<0.05)$ in group $A(0.201 \mathrm{~mL} / \mathrm{g} D M)$, whereas the lowest value for this fraction was observed in group $E$ $(0.029 \mathrm{~mL} / \mathrm{g} D M)$. The reason might be that $L$. chinensis was a high-quality forage with a higher NDF content (Table 1) and the rapid degradation of soluble carbohydrates increased the gas production rate in the early stages (Cone and van Gelder, 1999). The rate of gas production (c) in group $C$ was higher than groups $B, D$ and $E$, This could be due to the reason that the proper addition of $U$. cannabina can promote the balance of energy and protein in the substrate, which further promote the reproduction of rumen microorganisms (Tang et al. 2005) and thus increase the gas production rate.

Similarly, the potential gas production $(a+b)$ was higher for group A than group $\mathrm{E}(P<0.05)$. Khazaal et al. (1993) pointed out that feed intake is mainly explained by the rate of gas production $(c)$, which affects the pass rate of feed through the rumen and the potential gas production $(a+b)$ is related to the degradability of the feed. Therefore the higher values of potential gas production in groups $A$ and $C$ might indicate a better nutrient availability for rumen microorganisms (Nsahlai et al. 1994).

\section{Effects on the fermentation parameters in vitro}

In Fig 2(a), the pH value in all groups was within the normal range during the $24 \mathrm{~h}$ fermentation. However, the $\mathrm{pH}$ values at $1 \mathrm{~h}, 3 \mathrm{~h}$ and $6 \mathrm{~h}$ were increased in groups $A$ and $C$; and at $24 \mathrm{~h}$ were observed highest in group $C(P<0.05)$. The reason might be that the crude protein of $U$. cannabina was higher and the digestible protein was up to $70 \%$. A certain addition of $U$. cannabina can increase the digestible protein in the fermentation substrate and a large amount of protein degradation promotes the increase of ammonia nitrogen concentration and finally lead to the increased the $\mathrm{pH}$ value. It was found that addition of $U$. cannabina $(100 \mathrm{mg} / \mathrm{g})$ can prevent the effects of rumen acidosis effectively, by increasing the $\mathrm{pH}$ value of rumen fluid to $30 \%$ in vitro (Kleim et al. 2017). Similarly, Arroquy et al. (2004) reported that as the ratio of rumen degradable protein (RDP) increased, the $\mathrm{pH}$ value was also increased linearly within the normal range.

In Fig 2(b), the ammonia nitrogen concentration in all groups was all within the normal range during the $24 \mathrm{~h}$ fermentation. However, the ammonia nitrogen in groups $D$ and $E$ was higher at $3 \mathrm{~h}, 6 \mathrm{~h}, 12 \mathrm{~h}$ and $24 \mathrm{~h}$. The concentration of ammonia nitrogen is determined by the rumen microbial 
(a)

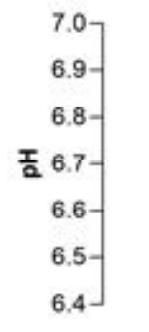

(c)

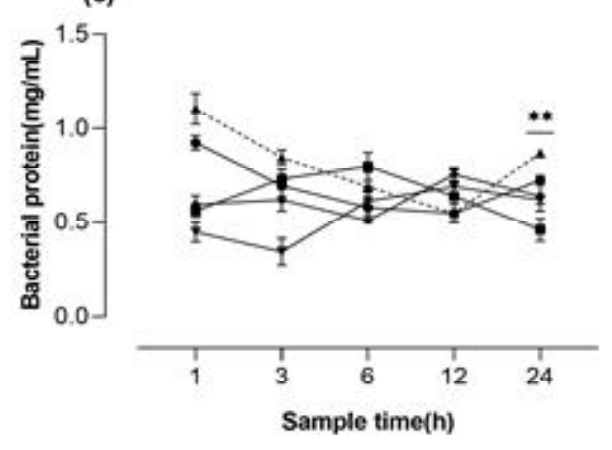

(b)

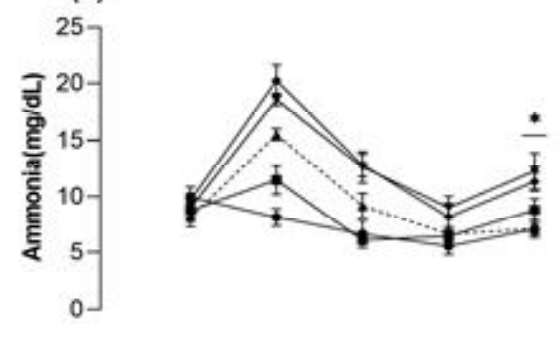

(d)

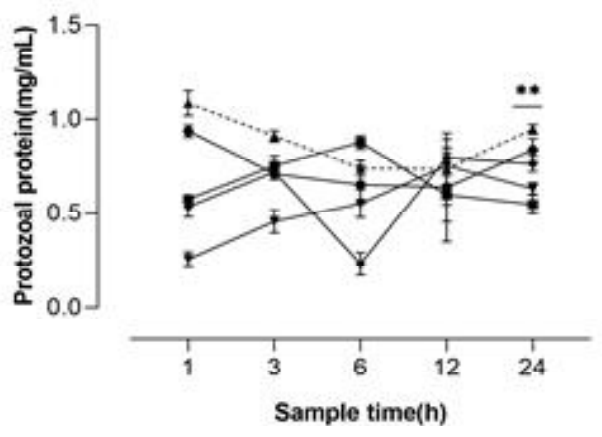

Fig 2: The effect of $U$. cannbinau to $L$. chinensis ratios on $\mathrm{pH}$ value(a), ammonia(b), bacterial protein(c), protozoal protein (d) in vitro. Legends: Ratio of $U$. cannabina to $L$. chinensis in groups A-E are 0:100, 30:70, 50:50, 70:30 and 100:0 respectively.

*indicates differences between treatments at $p<0.05$; ${ }^{* *}$ indicates differences between treatments at $p<0.01$.

decomposition of proteins and the rate at which ammonia is used to synthesize microbial proteins. Groups D and E contained higher CP and NFCs contents (Table 1), which lead to higher ammonia nitrogen synthesis. At $24 \mathrm{~h}$, the ammonia nitrogen concentration in group $C$ decreased significantly $(P<0.05)$, due to the increased ratio of NDF and NFCs and decreased lignin concentration (Table 1) leading to suitable conditions for microbial growth and protein synthesis (Shen et al. 2017).

\section{Effects on the contents of bacterial and protozoal proteins in vitro}

As it can be seen in Fig 2 (c,d), the concentration of bacteria and protozoa protein was higher in groups $A$ and $C$ at $1 \mathrm{~h}, 3$ $\mathrm{h}$ and $6 \mathrm{~h}$. The reason might be that $L$. chinensis has highquality forage contents which are more conducive for microbial growth. Stern et al. (1994) reported that energy and nitrogen balance and simultaneous release of them in the diet determine the growth of rumen microbes, which could change the synthesis efficiency of MCP (bacteria and protozoa protein). In the beginning, the supply of energy and nutrients in the substrate was sufficient to meet the needs of the microorganisms. Fermentation produced a large amount of energy and precursors required for the synthesis of self-proteins by microorganisms such as ammonia, volatile fatty acids and ATP (Van Soest, 1994). As time went on, the gradual consumption of nutrients and energy and the proliferation of bacteria had reached a stationary stage. In addition, the phagocytosis of protozoa was enhanced, the production of bacterial proteins in the rumen began to decrease and it might also be caused by bacteriolysis (Sherwood et al. 2012).

The comparison among the groups showed that with the increased ratio of $U$. cannabina and the decreased ratio of $L$. chinensis, the bacterial and protozoal protein concentrations were decreased. However, this concentration was observed highest in group $\mathrm{C}$ at $24 \mathrm{~h}$. This could be due to the certain complementary interaction effect of $U$. cannabina and L. chinensis nutrients (Haddad, 2000), which promotes the balance of energy and protein in the substrate by influencing the overall increased microbial protein synthesis. It can also be inferred that with the passage of culture time the protozoal protein concentration fluctuated greatly in the groups $D$ and $E$. It is speculated that some pharmacological effects of $U$. cannabina changes the rumen microbiota (Yang et al. 2013).

\section{CONCLUSION}

Based on the results of current experiment, the 50:50 ratio of Urtica cannabina and Leymus chinensis increased the gas production in goat rumen microorganisms in vitro. Besides, this group increased the $\mathrm{pH}$ value and microbial protein contents; and decreased the ammonia nitrogen concentration in culture solution. Therefore, the 50:50 ratio of Urtica cannabina and Leymus chinensis could potentially be favorable for fermentation and gas production of rumen microorganisms as shown in the in vitro studies. 


\section{ACKNOWLEDGEMENT}

We are thankful to the National 13th Five-Year Plan Key Research and Development Program (2018YFD0502100), National Natural Science Foundation (31402119) and the Priority Academic Program Development of Jiangsu Higher Education Institutions (PAPD), P.R. China for supporting the current study.

\section{REFERENCES}

Arroquy, J.I., Cochran, R.C., Wickersham, T.A., Llewellyn, D.A., Titgemeyer, E.C., Nagaraja, T.G. and Johnson, D.E. (2004). Effects of type of supplemental carbohydrate and source of supplemental rumen degradable protein on low quality forage utilization by beef steers. Animal Feed Science and Technology. 115: 247-263.

Bourgeois, C., Leclerc, É.A., Corbin, C., Doussot, J., Serrano, V., Vanier, J.R., Seigneuret, J.M., Auguin, D., Pichon, C., Lainé, É., Hano, C. (2016). Nettle (Urtica dioica L.) as a source of antioxidant and anti-aging phytochemicals for cosmetic applications. Comptes Rendus Chimie. 19: 1090-1100.

Carvalho, A.R., Costa, G., Figueirinha, A., Liberal, J., Prior, J.A.V., Lopes, M.C., Cruz, M.T. and Batista, M.T. (2017). Urtica spp.: Phenolic composition, safety, antioxidant and antiinflammatory activities. Food Research International. 99: 485-494.

Cone, J.W. and van Gelder, A.H. (1999). Influence of protein fermentation on gas production profiles. Animal Feed Science and Technology. 76: 251-264.

Haddad, S.G. (2000). Associative effects of supplementing barley straw diets with alfalfa hay on rumen environment and nutrient intake and digestibility for ewes. Animal Feed Science and Technology. 87: 163-171.

Hall, M.B. and Herejk, C. (2001). Differences in yields of microbial crude protein from in vitro fermentation of carbohydrates. Journal of Dairy Science. 84: 2486-2493.

Humphries, D.J. and Reynolds, C.K. (2014). The effect of adding stinging nettle (Urtica dioica) haylage to a total mixed ration on performance and rumen function of lactating dairy cows. Animal Feed Science and Technology. 189: 72-81.

Jin, Y.M., Jiang, C., Zhang, X.Q., Shi, L.F. and Wang, M.Z. (2018). Effect of dietary Urtica cannabina on the growth performance, apparent digestibility, rumen fermentation and gastrointestinal morphology of growing lambs. Animal Feed Science and Technology. 243: 1-9.

Khazaal, K., Markantonatos, X., Nastis, A. and Ørskov, E.R. (1993). Changes with maturity in fibre composition and levels of extractable polyphenols in Greek browse: Effects on in vitro gas production and in sacco dry matter degradation. Journal of the Science of Food and Agriculture. 63: 237-244.

Kliem, K.E., Morgan, R. and Mould, F.L. (2017). The effect of Lactuca sativa and Urtica dioica on in vitro acidosis. Proceedings of the British Society of Animal Science. 2005: 226-226.
Menke, K.H. and Steingass, H. (1988). Estimation of the energetic feed value obtained from chemical analysis and in vitro gas production using rumen fluid. Animal Research and Development. 28: 7-55.

Nsahlai, I.V., Siaw, D. and Osuji, P.O. (1994). The relationships between gas production and chemical composition of 23 browses of the genus Sesbania. Journal of the Science of Food and Agriculture. 65: 13-20.

Ørskov, E.R. and McDonald, I. (1979). The estimation of protein degradability in the rumen from incubation measurements weighted according to rate of passage. Journal of Agricultural Science. 92:499-503.

Shen, H., Lu, Z.Y., Xu, Z.H., Chen, Z. and Shen, Z.M. (2017). Associations among dietary non-fiber carbohydrate, ruminal microbiota and epithelium G-protein-coupled receptor and histone deacetylase regulations in goats. Microbiome. 5: 123.

Sherwood, L., Klandorf, H. and Yancey, P. (2012). Animal physiology: from genes to organisms, $2^{\text {nd }}$ edn. Belment, California.

Stern, M.D., Varga, G.A., Clark, J.H., Firkins, J.L., Huber, J.T. and Palmquist, D.L. (1994). Evaluation of Chemical and Physical Properties of Feeds That Affect Protein Metabolism In the Rumen. Journal of Dairy Science. 77: 2762-2786.

Tang, S.X., Jiang, H.L., Zhou, C.S. and Tan, Z.L. (2005). Effects of different forage species on in vitro gas production characteristics. Acta Prataculturae Sinica. 14: 72-77.(in Chinese).

Van Soest, P.J. (1994). Nutritional Ecology of the Ruminant, $2^{\text {nd }}$ edn. Cornell University, Ithica, New York.

Weatherburn, M.W. (1967). Phenol-hypochlorite reaction for determination of ammonia. Analytical Chemistry. 39: 971974.

Xie, F., Zhang, L., Jin, W., Meng, Z., Cheng, Y., Wang, J. and Zhu, W. (2019). Methane Emission, Rumen Fermentation and Microbial Community Response to a Nitrooxy Compound in Low-Quality Forage Fed Hu Sheep. Current Microbiology. 76: 435-441.

Yang, C.L.H., Or, T.C.T., Ho, M.H.K. and Lau, A.S.Y. (2013). Scientific Basis of Botanical Medicine as Alternative Remedies for Rheumatoid Arthritis. Clinical Reviews in Allergy and Immunology. 44: 284-300.

Zhang, X.O. and Zhao, S.Z. (2008). Nutritional function and silage characteristics of Urtica cannabina. Animal Husbandry and Feed Science. 4: 11-13. (in Chinese).

Zhang, X.Q., Jin, Y.M., Wang,Y.Q., Gao,F.Q. and Qi,J. (2014). Effects of inoculants and molasses on silage quality of nettle (Urtica cannabina). Journal of Animal and Veterinary Advances. 16: 33-40.

Zhang, X.Q., Jin, Y.M., Zhang, Y.J., Yu, Z. and Yan, W.H. (2014). Silage quality and preservation of Urtica cannabina ensiled alone and with additive treatment. Grass and Forage Science. 69: 405-414.

Zhang, Z., Wang, S., Wang, M., Shahzad, K., Zhang, X., Qi, R. and Shi, L. (2020). Effects of Urtica cannabina to Leymus chinensis ratios on ruminal microorganisms and fiber degradation in vitro. Animals. 10: 335. 